\title{
NOTAS SOBRE A CONCEPÇ̃̃O DE EXPERIÊNCIA NO JOVEM WALTER BENJAMIN
}

\author{
Fernando Araújo Del Lama ${ }^{1}$ \\ Universidade de São Paulo
}

Resumo: Apesar das várias transformações e rearranjos conceituais que acometeram o problema da experiência (Erfahrung) ao longo do percurso intelectual de Walter Benjamin, trata-se ainda de um dos poucos temas que perpassa toda sua obra. Com efeito, o conceito benjaminiano de experiência carrega certas peculiaridades em relação à inserção estrita no interior de uma reflexão sobre o conhecimento, como fizeram Aristóteles e Kant. Para além dessa restrição, ele se enquadra em uma dimensão mais ampla da relação entre homem e mundo, compreendendo características relativas ao conhecimento, à ação, à sensibilidade, à comunicação, à fé, dentre outros aspectos da experiência humana predominantes ao longo de um determinado contexto histórico, cultural e social. Em meio a isso, pode ser identificada uma tendência que orienta suas reflexões, desde os escritos produzidos nos tenros anos de juventude até aqueles redigidos sob o horizonte sombrio da Europa dos anos 30, a saber, a posição crítica em relação à experiência de seu próprio tempo. Em 1913, em um de seus primeiros escritos, intitulado precisamente "Experiência", Benjamin critica a vulgaridade filisteia e a falta de sentido com as quais os adultos costumam agir no início do século XX. Eles dedicam suas vidas a frustrar e suprimir sonhos e aspirações juvenis, relegando-os a mera animosidade que aquece todos os espíritos joviais e desaparece inevitavelmente com o estabelecimento da vida adulta: "mascarados" por uma experiência imóvel e impenetrável, os adultos se armam contra os argumentos dos jovens que procuram se emancipar de sua tutela intelectual. Alguns anos depois, precisamente entre 1917 e 1918, em Sobre o programa da filosofia vindoura, Benjamin elabora uma crítica ao sistema de Kant, especialmente ao caráter matemático-mecânico limitado e empobrecido de seu conceito de experiência, supostamente influenciado pela Weltanschauung do lluminismo. Benjamin propõe uma reforma da filosofia pela extensão da perspectiva kantiana através da fundação de um conceito metafísico de experiência, que incluiria não só o conhecimento, mas também a arte, a história e a religião; é uma substituição do paradigma matemático-mecânico por um baseado na dimensão criativa da linguagem que permite tal extensão. Ao longo da década de 30, o problema da experiência desempenha novamente um papel central nas obras de Benjamin, enquanto declínio da experiência coletiva. Suas reflexões durante esse período examinam as consequências históricas, políticas e sociais de tal declínio, bem como formulam um diagnóstico crítico de uma nova e ascendente configuração da experiência, cujo nome é vivência (Erlebnis). Todavia, pretende-se concentrar neste artigo apenas no período inicial, marcado por uma perspectiva idealista; não obstante isso, discute-se também alguns pontos que permitem conectar essa perspectiva inicial aos desenvolvimentos materialistas dos escritos tardios.

Palavras-chave: Walter Benjamin. Experiência. Juventude. Idealismo. Iluminismo.

\footnotetext{
${ }^{1}$ Doutorando em Filosofia com pesquisa fomentada pela FAPESP. E-mail: dellama.f@gmail.com
}

\section{Blucher}




\title{
Notes on young Walter Benjamin's conception of experience
}

\begin{abstract}
Despite the several transformations and conceptual rearrangements that affected the problem of experience (Erfahrung) along Walter Benjamin's intellectual journey, it is still one of the few themes that remain throughout his work. Indeed, Benjamin's concept of experience holds some peculiarities about the strict insertion of reflection on knowledge, as Aristotle and Kant have done. Beyond this restriction, it fits into a broader dimension of the relation between man and world, comprising the features with regard to knowledge, action, sensibility, communication, faith and other aspects of human experience, prevailing throughout a given historical, cultural and social context. In the midst of this, may be identified an aspect that guides his reflections, from the writings produced in the tenderyears of youth to those written under the gloomy horizon of the Europe of the 30s, namely, the critical position about the experience of his own time. In 1913, in one of his earliest writings, precisely entitled "Experience", Benjamin criticizes the philistine vulgarity and meaninglessness with which adults use to act in the early twentieth century. They devote their lives to frustrate and suppress youthful dreams and aspirations, relegating them to mere animosity that warms all young spirits and inevitably fades away with the onset of adulthood: "masked" by an immovable and impenetrable experience, the adults arm themselves against the arguments of young people who seek to emancipate themselves from their intellectual guardianship. In this text, Benjamin's answer sounds highly idealistic: it consists in seeking ground on something "inexperienceable" that transcends the gray world dominated by adults. After a few years, precisely between 1917 and 1918, Benjamin retakes the theme of experience and radicalizes the idealism of his position. In a short article entitled On the Program of Coming Philosophy, he elaborates a critique to Kant's system, especially to the limited and impoverished mathematical-mechanical character of its concept of experience, supposedly influenced by the Weltanschauung of the Enlightenment. Benjamin draws attention to the dazzling character of this experience, which blinds the spirits to its potentialities and prevents their accomplishment. Thus, he proposes a reform of philosophy by the extension of Kant's perspective through the foundation of a metaphysical concept of experience, which would include not only knowledge, but also art, history and religion; it is a substitution of the mathematical-mechanical paradigm by one based on the creative dimension of language that enables such extension. Throughout the 1930s, the problem of experience plays again a central role in Benjamin's works, namely as the decline of collective experience. His reflections during this period examine the historical, political, and social consequences of such decline, as well as formulate a critical diagnosis of a new and ascending configuration of experience, whose name is lived experience (Erlebnis). However, we intend to focus in this work only on the early period, characterized by an idealistic perspective; although this, we also discuss some points that allow us to connect such early perspective to the materialistic developments of the late writings.
\end{abstract}

Keywords: Walter Benjamin. Experience. Youthness. Idealism. Enlightenment.

\section{Blucher}


Ao longo de sua obra, Walter Benjamin² mostrou bastante precocemente certa preocupação, acompanhada de indícios claros de insatisfação com a situação moderna da experiência, bem como anseios de transformá-la radicalmente, ainda que dotados inicialmente de uma postura eminentemente idealista. Dois escritos de sua juventude se destacam nesse sentido: o opúsculo "Experiência", de 1913, e o artigo acerca da filosofia kantiana Sobre o programa da filosofia vindoura, redigido entre 1917 e 1918, os quais serão examinados mais profundamente nas próximas páginas.

A exposição foi dividida em três etapas. Em primeiro lugar, o texto se foca no ensaio "Experiência", sobretudo na crítica de Benjamin ao cerceamento do vigor jovial em busca de uma experiência alternativa àquela promovida pelos adultos. Em segundo lugar, são recuperadas algumas premissas que orientam a argumentação de Benjamin no artigo Sobre o programa da filosofia vindoura, conectando-as a aspectos centrais de sua filosofia da linguagem, tal como expostos em um artigo da mesma época, intitulado Sobre a linguagem em geral e sobre a linguagem do homem. Em terceiro lugar, são avaliados os possíveis ecos das formulações do jovem Benjamin acerca da experiência em suas formulações maduras sobre este tema, atentando para os efeitos sobre elas de suas guinadas teóricas.

\footnotetext{
${ }^{2}$ Os textos de Walter Benjamin são citados de acordo com a edição Gesammelte Schriften, estabelecida por Rolf Tiedemann e Hermann Schweppenhäuser e editada em sete volumes pela editora Suhrkamp entre 1972 e 1991, abreviada por GS, seguida da indicação do volume em algarismos romanos e do tomo em algarismos arábicos, além da página, também em números arábicos. Quando necessário, são indicadas na sequência, entre colchetes, ano e página das traduções utilizadas, as quais podem ser conferidas nas referências bibliográficas ao final do texto.
} 
Em um de seus primeiros escritos, influenciado pelas ideias do pedagogo alemão Gustav Wyneken e movido pelo ímpeto de insatisfação característico dos jovens, Benjamin dirige severas críticas a um tipo de experiência imposto pelos adultos, caracterizado pela imobilidade sufocante e pela arbitrariedade com a qual é estabelecida. Ele brada contra ela nos seguintes termos:

Travamos nossa luta por responsabilidade contra um ser mascarado. A máscara do adulto se chama "experiência". Ela é inexpressiva, impenetrável, sempre a mesma. Esse adulto já vivenciou tudo: juventude, ideais, esperanças, mulheres. Foi tudo ilusão. Ficamos, com frequência, intimidados ou amargurados. Talvez ele tenha razão. 0 que podemos objetar-lhe? Nós ainda não experimentamos nada (BENJAMIN, GS II-1, p. 54 [2002, p. 21).

A ironia contida nestas afirmações é deslindada na sequência, quando Benjamin passa a examinar como agem esses adultos por trás da "máscara de experiência", responsável por blindálos das críticas juvenis: a recusa do ímpeto e do frescor das ideias da juventude é fundada no fato de que o adulto já teve os mesmos pensamentos, mas "superou-os" ao adentrar à vida adulta. "Ele desvaloriza os anos que estamos vivendo, converte-os na época das doces asneiras que se cometem na juventude, ou no êxtase infantil que precede a longa sobriedade da vida séria" (BENJAMIN, GS II-1, p. 54 [2002, pp. 21-2]). Tal postura, marcada por um conservadorismo patente e por resignação quanto a falta de sentido que impregna sua vida adulta, faz com que o adulto-filisteu, aquele que "rejubila-se apenas com todo fato que demonstra de novo a falta de sentido" (BENJAMIN, GS II-1, p. 55 [2002, p. 23]), tolha as aspirações dos jovens: "uma vez que o filisteu jamais levanta os olhos para as coisas grandiosas e plenas de sentido, a experiência transformouse em seu evangelho" (BENJAMIN, GS II-1, p. 55 [2002, pp. 22-3]), a qual ele professa tão cega e dogmaticamente quanto os mais fervorosos religiosos.

\section{Blucher}


Os caminhos apontados por Benjamin possuem um alto teor idealista ou metafísico. "Sabemos que existe a verdade", diz ele,

ainda que tudo o que foi pensado até agora seja equivocado. Sabemos que a fidelidade precisa ser sustentada, ainda que até agora ninguém a tenha sustentado. Nenhuma experiência pode nos privar dessa vontade. Mas, será que em um ponto os pais teriam razão com os seus gestos cansados e sua desesperança arrogante? Será necessário que o objeto da nossa experiência seja sempre triste, que não possamos fundar a coragem e 0 sentido senão naquilo que não pode ser experimentado? (BENJAMIN, GS II-1, p. 55 [2002, pp. 22-3])

Benjamin precisa apostar em algo "não experimentável", visto que tudo o que o mundo moderno pode oferecer ao espírito é carregado de tristeza, desconsolo e ausência de sentido: "cada uma de nossas experiências possui efetivamente conteúdo. Nós mesmos conferimos-Ihe conteúdo a partir do nosso espírito. (...) A experiência é carente de sentido e espírito apenas para aquele já desprovido de espírito" (BENJAMIN, GS II-1, p. 55 [2002, p. 23]). 0 filisteu abomina tudo o que the faz referência aos seus sonhos juvenis, pois eles se apresentam a ele como uma convocação do espírito: "a juventude lhe é a lembrança eternamente incômoda dessa convocação. Por isso ele a combate", uma vez que, afinal, "vivenciar' sem o espírito é confortável, embora funesto" (BENJAMIN, GS II-1, p. 56 [2002, p. 24]). No entanto, é justamente a possibilidade de buscar coisas não vulgares, espirituais, que anima o texto de Benjamin: como bem observa Caroline Mitrovitch, "desde os textos de juventude, Benjamin se preocupa em elaborar um conceito de experiência articulado à construção de novas categorias de temporalidade, relacionadas à valorização do presente e, por conseguinte, à crítica de um passado eternizado quanto de futuros que cantam"; 
Notas sobre a concepção de experiência no jovem Walter Benjamin

no opúsculo em questão, o objetivo de Benjamin é "pensar um novo conceito de experiência que se reconcilie com a perspectiva do novo, recuperando sua dimensão original de tentativa e de risco" (MITROVITCH, 2011, p. 64). Essa abertura às possibilidades irrealizadas e ao advento do novo ${ }^{3}$ está implicada na forma de experiência que Benjamin almejava buscar: "(...) conhecemos uma outra experiência (eine andere Erfahrung). Ela pode ser hostil ao espírito e aniquilar muitos sonhos florescentes. No entanto, é o que existe de mais belo, de mais intocável e inefável, pois ela jamais estará privada de espírito se nós permanecermos jovens" (BENJAMIN, GS II-1, p. 56 [2002, p. 24]). Thomas Weber, no verbete "Erfahrung" dos Benjamins Begriffe, sintetiza o teor do opúsculo ao dizer que "a experiência dos adultos é uma [experiência] inautêntica (uneigentlich). Já o título coloca a palavra entre aspas. É a 'máscara' verbal com a qual o pequeno burguês camufla sua vida 'desconsolada e sem sentido': 'anos de compromissos, pobreza de ideias e lassidão (Schwunglosigkeit)', 'vulgaridade da vida', propensão ao 'eternamente-ontem (Ewig-Gestrigen)', 'a experiência eternamente única da ausência de espírito, etc'"' (WEBER, 2000, p. 231).

\footnotetext{
${ }^{3}$ Uma das "centelhas" que emergem a partir do choque entre Benjamin e Heidegger pode ser facilmente reportada às divergências de ambos em relação a concepção de experiência; mais especificamente, em relação à passividade/atividade que determina a experiência nas diferentes concepções de ambos. "Fazer uma experiência com algo, seja com uma coisa, com um ser humano, com um deus, significa", segundo Heidegger, "que esse algo nos atropela, nos vem ao encontro, chega até nós, nos avassala e transforma. 'Fazer' não diz aqui de maneira alguma que nós mesmos produzimos e operacionalizamos a experiência. Fazer tem aqui 0 sentido de atravessar, sofrer, receber o que nos vem ao encontro, harmonizando-nos e sintonizando-nos com ele. É esse algo que se faz, que se envia, que se articula" (HEIDEGGER, 2003, p. 121). Em Benjamin, dos primeiros aos últimos escritos, ao contrário da passividade heideggeriana, é patente a postura ativa na construção de uma nova experiência - individual e idealista nos escritos iniciais, e que assume, na década de 30, os contornos coletivos da práxis marxista. ${ }^{4}$ A interpretação da experiência dos adultos, já nesse escrito de juventude, como "experiência inautêntica" é interessante, pois permite uma série de relações com suas reflexões de maturidade sobre a experiência: Thomas Weber parece sugerir - em consonância com Kátia Muricy, como será explorado mais adiante - aproximações possíveis entre a "experiência" do adultofilisteu e a "experiência inautêntica" da maturidade, a qual Benjamin chamará de "vivência" (Erlebnis). É possível, do mesmo modo, que Weber considere que todo o tipo de experiência que não seja aquela almejada por Benjamin possa ser definido como inautêntica, o que, sem aproximações precipitadas, responde esta questão.
}

\section{Blucher}


Alguns anos mais tarde, em seu ensaio de 1917-18, Benjamin radicalizará o idealismo de sua posição: se outrora, embora acreditasse na existência de uma verdade, Benjamin não era capaz de localizá-la e identificá-la, desta vez, ele pretende fundar, recaindo em um pretenso dogmatismo, uma nova metafísica. Não se pretende, devido ao escopo principal deste trabalho, esmiuçar os detalhes a respeito deste ensaio, mas apenas identificar, em linhas bastante gerais, as ideias mais fundamentais nele contidas, além de chamar a atenção para alguns pontos passíveis de conexão com suas reflexões posteriores ${ }^{5}$. 0 objetivo central de Benjamin neste ensaio é devolver a filosofia ao seu lugar de Ciência Primeira, fazendo-a alcançar sua "supremacia sistemática (...) tanto sobre toda a ciência quanto sobre a matemática" (BENJAMIN, GS II-1, p. 168). Benjamin argumenta que, para tanto, o ponto de partida seria uma "depuração (Reinigung) da teoria do conhecimento" (BENJAMIN, GS II-1, p. 163) kantiana em seus dois âmbitos, ou seja, tanto pelo lado do epistemológico - o conceito de conhecimento - quanto pelo lado ontológico - 0 conceito de experiência. Ele especula que a filosofia vindoura deverá se basear, por um lado, na "conversão da 'experiência' em 'metafísica'" através de um "conceito superior de experiência", que abranja em si outros domínios do conhecimento, como a "arte, doutrina do direito e história", além da religião, segundo Benjamin, "o mais elevado desses campos"; por outro lado, dever-se-ia "fundar a esfera do conhecimento de modo autônomo, além da terminologia sujeito-objeto" (BENJAMIN, GS II-1, pp. 167-9).

\footnotetext{
${ }^{5}$ Para um estudo detalhado a respeito deste ensaio, ver OLIVEIRA, 1999.
} 
Aqui, o arsenal crítico de Benjamin é direcionado a outro aspecto da noção de experiência, que de certo modo se relaciona à crítica do ensaio anterior. 0 alvo das investidas de Benjamin é, certamente, o teor cientificista e redutor da concepção de experiência do lluminismo, "de que o pensamento de Kant participa inconscientemente" (WEBER, 2000, p. 234), que serviuIhe ali, via Herman Cohen ${ }^{6}$, de bode expiatório:

0 que constitui a inferioridade e a pouca profundidade da experiência daquele tempo, onde reside seu peso assombrosamente diminuto em termos especificamente metafísicos, somente será visível na percepção de como este conceito inferior de experiência também influenciou o pensamento kantiano, limitando-0. Evidentemente, trata-se do mesmo fato, frequentemente salientado como a cegueira religiosa e histórica do lluminismo, sem que se tenha reconhecido em que sentido essas características do lluminismo pertencem à Modernidade como um todo (BENJAMIN, GS II-1, p. 159).

A conexão com o opúsculo de 1913 se dá na medida em que a crítica apresentada aqui, como a de outrora, se dirige ao tolhimento das possibilidades comportadas pela "verdadeira" experiência, alterando apenas o objeto da crítica: no primeiro, a autoridade mascarada do adultofilisteu; neste último, os anseios de quantificação e a necessidade de certeza (e certificação) em relação à experiência ${ }^{7}$, que corta pela raiz qualquer outra possibilidade que escape a estas esferas.

\footnotetext{
${ }^{6}$ É preciso fazer um esclarecimento: a interpretação benjaminiana do sistema kantiano está bastante marcada pelos pilares estabelecidos a partir do livro Teoria da experiência de Kant, de Hermann Cohen. Segundo os relatos de Scholem (ver os capítulos iniciais de SCHOLEM, 2008), os contatos mais profundos de Benjamin com o criticismo kantiano foram mediados por este livro. É digna de menção, também, a nota 17 em WEBER, 2000, p. 235.

${ }^{7}$ Algo em completa consonância com aquilo que Max Weber, o grande teórico da modernidade, compreendera através dos conceitos de racionalização e de dominação pelo cálculo, correspondentes a processos fundantes da era moderna.
}

\section{Blucher}


Do mesmo modo, as soluções encontradas em ambos os contextos se mantêm no interior de um quadro idealista, que se radicaliza paulatinamente: a "verdade" não experimentável, apenas postulada no primeiro dos escritos, é localizada, no segundo, como um conceito superior, metafísico de experiência, ainda por ser desenvolvido.

Os caminhos de tal desenvolvimento são indicados nas últimas linhas de seu artigo, nas quais Benjamin esboça uma via para a reorientação da filosofia moderna, a saber, substituir 0 parâmetro matemático-mecânico do conhecimento por um baseado em uma relação entre conhecimento e linguagem.

Tal como a própria doutrina kantiana que, para encontrar seus princípios, teve de ver-se diante de uma ciência, com relação a qual pôde defini-los, algo semelhante passou-se com a filosofia moderna. A grande transformação (Umbildung) e correção a serem realizadas em relação ao conceito de conhecimento orientado unilateralmente para o matemático-mecânico, somente podem ser obtidas por meio de uma relação do conhecimento com a linguagem, tal como tentou realizar Hamann ainda durante o tempo de vida de Kant. Para além da consciência de que o conhecimento filosófico é absolutamente certo e apriorístico, para além da consciência destes aspectos da filosofia equivalentes à matemática, ficou completamente aquém para Kant 0 fato de que todo o conhecimento filosófico tem sua expressão unicamente na linguagem e não em fórmulas e números (BENJAMIN, GS II-1, p. 168).

Ora, não por acaso é dessa mesma época o ensaio Sobre a linguagem em geral e sobre a linguagem do homem, cujo conjunto de ideias pode auxiliar na compreensão deste ponto. Embebido de teologia, Benjamin sustenta neste ensaio, comentando o livro bíblico do Genesis, 
uma distinção entre duas variantes de linguagem. Grosso modo, há a linguagem que nomeia, comunicadora da essência, propriamente divina. Benjamin a caracteriza do seguinte modo:

Nesse "Haja" e no "Ele chamou" [da palavra divina], no início e no fim dos atos, aparece, a cada vez, a profunda e clara relação do ato criador com a linguagem. Este começa com a onipotência criadora da linguagem, e ao final a linguagem, por assim dizer, incorpora a si o criado, ela o nomeia. Ela é aquilo que cria, e perfaz, ela é palavra e nome. Em Deus o nome é criador por ser palavra, e a palavra de Deus é saber por ser nome (BENJAMIN, GS II-1, p. 148[2011, p. 61]).

A linguagem humana, em contrapartida é caracterizada por um uso meramente instrumental, que se vale de palavras que buscam comunicar algo externo a ela, operando, assim, apenas como mediadora. Esta é a linguagem decaída, separada do potencial criador do Verbo divino. Benjamin marca as diferenças entre os dois registros de linguagem da seguinte forma:

A palavra deve comunicar alguma coisa (afora de si mesma). Esse é realmente 0 pecado original do espírito linguístico. A palavra que comunica do exterior, expressamente mediada, é de certa forma uma paródia da palavra imediata, da palavra criadora de Deus; é também a queda do espírito adâmico, do espírito linguístico bem-aventurado, que se encontra entre ambos (BENJAMIN, GS II-1, p. 153 [2011, p. 67]).

A concepção de linguagem que ampararia a transformação necessária para que a filosofia vindoura cumpra seu programa é, certamente, a linguagem divina. Seu potencial inerente de abertura de significado e criação de sentido seria o responsável por redimir a filosofia, que ao

\section{Blucher}


assumir uma concepção instrumental da linguagem, eminentemente humana, empobreceu e vulgarizou a concepção moderna de experiência. Afinal, "a infinitude de toda linguagem humana permanece sempre de natureza limitada e analítica em comparação com a infinitude absoluta, ilimitada e criadora da palavra divina" (BENJAMIN, GS II-1, p. 149 [2011, p. 62]), de modo que só esta última é capaz de sustentar uma concepção de experiência como "multiplicidade unitária e contínua do conhecimento" (BENJAMIN, GS II-1, p. 168).

À guisa de conclusão, cabe observar que algumas destas formulações repercutirão na filosofia tardia de Benjamin. E, se é possível pensar que alguns elementos que circundam a problemática madura da experiência já se encontram inscritos, de algum modo, em seus primeiros escritos, é verdade que tal problemática ganhará uma nova roupagem, acompanhada de novos rumos e inflexões nos ensaios da década de $30^{8}$, como declínio da experiência coletiva. Prova cabal disso é a seguinte anotação, escrita provavelmente em 1929:

\footnotetext{
${ }^{8}$ Nesse ponto, vale retomar as observações de Kátia Muricy segundo as quais o âmbito do opúsculo de 1913 "é 0 da experiência individual; aqui se está distante da posterior amplitude do conceito, nos textos dos anos 30, enquanto categoria para se pensar a modernidade como perda do sentido coletivo da experiência transmissível. Também não se trata da compreensão que, em texto que escreverá poucos anos depois, irá opor à estreiteza do conceito kantiano de experiência, restrito ao domínio da física newtoniana - a de um conceito de experiência que pudesse alcançar a esfera da religião e da história. A compreensão de experiência no artigo juvenil é a corriqueira, a habitual acepção de experiência de vida individual: a dos mais velhos, a dos pais. Uma compreensão que se poderia a proximar daquela de vivência subjetiva que Benjamin definirá, em seus textos maduros, na noção de Erlebnis, a dimensão incomunicável da experiência na modernidade. 0 sentido dado por Benjamin no texto de 1913 é negativo: esta experiência é 0 argumento imobilizante do passado, a última palavra do adulto filisteu: 'ela é inexpressiva, impenetrável, sempre igual'. Na sua repetição, esta experiência não pode acolher o novo, o que irrompe quebrando a sua continuidade estéril. A rigor, não é uma experiência propriamente dita, já que não rompe os limites do mesmo. Devolver à experiência seu sentido autêntico significa reconciliá-la com o sentido original da palavra, ligando-a à quebra de limites e à emergência do novo" (MURICY, 2009, p. 44). Thomas Weber, do mesmo modo, é bastante claro ao marcar as diferenças
} 
Notas sobre a concepção de experiência no jovem Walter Benjamin

Num de meus primeiros ensaios mobilizei todas as forças rebeldes da juventude contra a palavra "experiência". E eis que agora essa palavra tornou-se um elemento de sustentação em muitas de minhas coisas. Apesar disso, permaneci fiel a mim mesmo. Pois o meu ataque cindiu a palavra sem a aniquilar. 0 ataque penetrou até 0 âmago da coisa (BENJAMIN, GS II-3, p. 902 [2002, p. 21].

Quando Benjamin diz, não obstante as críticas de sua juventude, que a palavra experiência se tornou um "elemento de sustentação" de seus trabalhos maduros, é preciso ponderar sobre o sentido desta afirmação. Não se trata, de modo algum, de um resgate irrestrito dos elementos outrora criticados; se se considerar seriamente a segunda metade da anotação, além da particularidade do termo "palavra", conclui-se que, cindida pelo ataque, é apenas uma dimensão da palavra "experiência" que assume conotações positivas, de modo que os ataques desferidos contra ela no ensaio de juventude permanecem ainda vigentes - 0 que garante a coerência e a "fidelidade a si mesmo".

Assim, deve-se entender que a crítica continua válida para a dimensão imobilizante e conservadora da relação com o tempo presente - que se tornará, nos escritos maduros, 0 "sempreigual" (Immergleichen), ligado ao fetichismo da mercadoria no contexto da vivência -,

\footnotetext{
substanciais no itinerário do conceito de experiência na obra de Benjamin, descrevendo-o da seguinte forma: "0 jovem Benjamin está confrontado com a 'experiência' como instância de apelação legitimadora do estabelecido, contra a qual ele reclama - em nome de uma fração do movimento jovem - por 'outro' conceito de experiência, cuja intenção contestadora somente poderia conceber e afirmar como metafísica. Com o fim da Primeira Guerra Mundial, esta intenção culmina em um programa de uma metafísica da experiência como lugar sistemático para uma reestruturação da filosofia. Com suas ambições acadêmicas frustradas e sua guinada (Wendung) anarco-comunista, a aspiração metafísica de Benjamin se transforma progressivamente em uma 'paixão dialética' pelo histórico-concreto" (WEBER, 2000, p. 230).
}

\section{Blucher}


resguardando, porém, a dimensão transformadora e de abertura de sentido com relação ao futuro, mediada pela ação valorizadora do presente, que a "outra experiência" buscada continha em si. E é justamente esta a dimensão da experiência que ficou imune aos ataques juvenis de Benjamin: permanecendo velada durante a década de 20, já que não precisou ser articulada conceitualmente, a necessidade de retomar tais investigações se deu mediante o contato mais estreito com a obra de Marx e o alargamento das problemáticas proporcionado pela perspectiva materialista, traduzido na relação entre experiência e vivência, Erfahrung e Erlebnis, que dará o tom dos desenvolvimentos teóricos de Benjamin na década de 30.

Ademais, apesar de tais ressonâncias entre fases distintas de seu percurso intelectual, é preciso estabelecer alguns limites: no conjunto de temas relacionados neste trabalho, o programa de 1917-18, baseado na fundação de um conceito metafísico de experiência, por exemplo, não recebe continuidade por parte de seu autor. Tal como afirma Thomas Weber: "Retrospectivamente, o escrito programático se esgota em seu gesto. Não se trata, de modo algum, do 'programa da filosofia vindoura de Walter Benjamin'. Sua crítica da filosofia da vida, formulada mais de vinte anos depois, pode ser lida, também, como uma autocrítica tácita" (WEBER, 2002, pp. 235-6) ${ }^{9}$. A

\footnotetext{
${ }^{9}$ Esta interpretação parece ser a mais condizente com os escritos benjaminianos. 0 kantiano Howard Caygill, por outro lado, pensa de modo diverso: em seu livro sobre Benjamin, ele diz que "a continuidade [temática] entre eles [0 trabalho sobre o drama barroco e a genealogia da modernidade desenvolvida nas Passagens] podem ser descritos nos termos do desenvolvimento de um conceito kantiano de experiência através de uma extensão de um método nietzschiano de niilismo ativo. Os temas da experiência e do niilismo são evidentes em todas as fases de sua produção, da obra da época do Movimento de Juventude (...) à obra marxista do início dos anos 30. (...) 0 Benjamin deste livro tenta estender 0 conceito de experiência deixado por Kant através de sua transformação em uma filosofia da história anti-hegeliana, porém especulativa, inspirada por um niilismo ativo nietzschiano. Este é um Benjamin cujo projeto é a exploração das possibilidades de uma experiência descontínua do absoluto, um projeto cujos inícios podem ser remontados a seus primeiros escritos e cujas implicações se desdobrarão no criticismo e na história cultural tardios" (CAYGILL, 1998, pp. xii-xiii). Ou seja: Caygill sugere que o ensaio sobre a filosofia vindoura determina toda a obra posterior de Benjamin, de modo que há diversas aproximações, um tanto quanto apressadas e presas a conviç̧ões prévias, entre textos absolutamente díspares e inseridos em outros contextos. Já Everaldo Vanderlei de Oliveira, em sua tese de doutorado, ao pensar os desdobramentos do escrito programático apenas em relação a trabalhos subsequentes de Benjamin -
} 
crítica da filosofia da vida é um dos temas que orientam as investigações vinculadas ao complexo das Passagens, ápice da reflexão materialista de Benjamin. Logo, a perspectiva idealista de juventude, sobretudo após o contato com a obra de Georg Lukács e o início da amizade com Asja Lacis, ambos no ano de 1924 e marcos de sua guinada teórica, foi abandonada em prol do advento e do amadurecimento do materialismo - daí que tal postura possa ser interpretada enquanto autocrítica. 0 que permanece intacto, porém, ao longo de toda a sua obra, é o desejo de transformar radicalmente a experiência da sociedade.

\section{Referências bibliográficas:}

BENJAMIN, W. Gesammelte Schriften. Hrsg. von Rolf Tiedemann und Hermann Schweppenhäuser. 7 Bände. Frankfurt am Main: Suhrkamp, 1972-1991.

"'Experiência"' in: Reflexões sobre a criança, o brinquedo e a educação. Tradução, apresentação e notas: Marcus Vinícius Mazzari; posfácio: Flávio Di Giorgi. São Paulo: Duas Cidades; Ed 34, 2002.

. "Sobre a linguagem em geral e sobre a linguagem do homem" in: Escritos sobre mito e linguagem (1915-1921). Organização, apresentação e notas: Jeanne Marie Gagnebin; tradução: Susana Kampff Lages e Ernani Chaves. São Paulo: Duas Cidades; Editora 34, 2011.

na verdade, um concomitante (a tese de doutorado sobre o romantismo alemão) e outro subsequente (o ensaio sobre As afinidades eletivas, de Goethe) -, ambos anteriores à reviravolta materialista, parece acertar em cheio quanto aos limites filosóficos implícitos em sua obra. Ele afirma, em sua tese de doutorado, que "temos de considerá-lo um escrito em aberto, nem concluído nem definitivo, sujeito portanto às múltiplas possibilidades e mudanças de rumo ou acento, aprofundamento do itinerário ou abandono de perspectivas" e que, "precisamente por ser um escrito em aberto que elabora e circunscreve o projeto a ser realizado e não é e nem pode ser sua execução concreta e detalhada, do ponto de vista do intérprete que sobre ele se debruça, como parte integrante da mesma fidelidade, exige-se que se tome heuristicamente o texto como se fosse realmente um "programa" e que se observe detalhadamente o que daí resulta, tanto no texto considerado em si mesmo quanto em seus possíveis desdobramentos nas produções seguintes" (OLIVEIRA, 2009, p. 30, grifos meus).

\section{Blucher}


CAYGILL, H. Walter Benjamin. The Colour of Experience. London; New York: Routledge, 1998.

HEIDEGGER, M. "A essência da linguagem" in: A caminho da linguagem. Tradução: Márcia Sá Cavalcante Schuback. Petrópolis: Vozes, 2003.

MITROVITCH, C. Experiência e formação em Walter Benjamin. São Paulo: UNESP, 2011.

MURICY, K. Alegorias da dialética. Imagem e pensamento em Walter Benjamin. Rio de Janeiro: Nau, 2009.

OLIVEIRA, E. V. Os conceitos de crítica e experiência no jovem Benjamin: o programa de 1917-18. Dissertação (Mestrado em Filosofia) - Faculdade de Filosofia, Letras e Ciências Humanas, Departamento de Filosofia, Programa de Pós-Graduação em Filosofia, Universidade de São Paulo, São Paulo, 1999.

Um mestre da crítica: romantismo, mito e lluminismo em Walter Benjamin. Tese (Doutorado em Filosofia) - Faculdade de Filosofia, Letras e Ciências Humanas, Departamento de Filosofia, Programa de Pós-Graduação em Filosofia, Universidade de São Paulo, São Paulo, 2009.

SCHOLEM, G. Walter Benjamin: a história de uma amizade. Tradução: Geraldo Gerson de Souza, Natan Nobert Zins e J. Guinsburg. São Paulo: Perspectiva, 2008.

WEBER, T. "Erfahrung", in: OPITZ, M.; WIZISLA, E. (Hrsg.). Benjamins Begriffe. 2 bd. Frankfurt am Main: Suhrkamp, 2000. 